Original article

\title{
Relationship between amputation and risk factors in individuals with diabetes mellitus: A study with Brazilian patients
}

\author{
Alessandra M. Mantovani ${ }^{a, *}$, Cristina E.P.T. Fregonesi ${ }^{\mathrm{b}}$, Mariana R. Palma ${ }^{\mathrm{c}}$, \\ Fernanda E. Ribeiro ${ }^{c}$, Rômulo A. Fernandes ${ }^{\mathrm{a}, \mathrm{d}}$, Diego G.D. Christofaro ${ }^{\mathrm{a}, \mathrm{d}}$ \\ a Postgraduate Program in Science Motricity, Institute of Biosciences, Universidade Estadual Paulista, Rio Claro, SP, Brazil \\ ${ }^{\mathrm{b}}$ Department of Physical Therapy, Faculty, Universidade Estadual Paulista, Presidente Prudente, SP, Brazil \\ c Postgraduate Program in Physical Therapy. Faculty of Science and Tecnology, Universidade Estadual Paulista, Presidente Prudente, SP, Brazil \\ d Professor of Department of Physical Education, Faculty of Science and Tecnology, Universidade Estadual Paulista, Presidente Prudente, SP, Brazil
}

A R T I C L E I N F O

Article history:

Received 28 June 2016

Accepted 22 August 2016

\section{Keywords:}

Diabetes mellitus

Risk factor

Diabetic neuropathy

Amputation

Diabetic foot

\begin{abstract}
A B S T R A C T
Individuals with diabetes develop lower extremity amputation for several reasons. Investigations into pathways to the development of complications are important both for treatment and prevention. Aim: To evaluate the relationship between amputation and risk factors in people with diabetes mellitus. Materials and method: All participants included in this study $(n=165)$ were recruited from the Diabetic Foot Program, developed in a Brazilian University, over seven years (2007-2014) and all information for this study was extracted from their clinical records.

Results: The prevalence of amputation in patients with diabetes with four risk factors was up to $20 \%$ higher when compared to those with only one risk factor. The main predictive risk factors for amputation in this population were the presence of an ulcer and smoking.

Conclusion: The risk factors for amputation can be predicted for people with diabetes mellitus and, in the present study, the main factors were the presence of an ulcer and the smoking habit.
\end{abstract}

(C) 2016 Diabetes India. Published by Elsevier Ltd. All rights reserved.

\section{Introduction}

Type 2 diabetes is a chronic metabolic disease associated with micro and macro vascular complications, including an increased risk of cardiovascular disease, diabetic nephropathy, retinopathy, neuropathy and lower extremity amputations [1,2]. Lower extremity amputation is an expensive and life-altering complication of diabetes [3]. The risk of amputation varies substantially according to ethnic group, sex, and geographical location [4]. About $34 \%$ of those who have an amputation will have a second more extensive one within 16 weeks of their initial amputation [5].

Individuals with diabetes develop lower extremity amputation for many reasons. Age, time of the disease, prolonged hyperglycemia, dyslipidemia, smoking habit, drinking alcoholic beverages, the presence of infections, peripheral neuropathy and prior vascular ulcers, together with poor metabolic control of the

\footnotetext{
* Corresponding author at: Endereço: Roberto Simonsen Avenue, 305, Centro Educacional, CEP: 19060-900. Presidente Prudente, São Paulo, Brasil.

E-mail address: leka_indy@hotmail.com (A.M. Mantovani).
}

disease, are some of the lower extremity amputation risk factors $[6,7]$.

The majority of lower extremity amputations are due to the development of a foot ulcer and the failure of that foot ulcer to heal. Studies have shown that about $90 \%$ of individuals with lower extremity amputation had a history of a foot ulcer and this factor is very often associated with peripheral vascular disease (PVD) and/ or diabetic peripheral neuropathy (DPN) of the lower extremity $[8,9]$. The survival rate for patients with diabetes following amputation is only about $50 \%$ after three years [6].

DPN of the foot leads to loss of the protective sensation, doubling the likelihood of developing a foot ulcer and tripling the risk of lower extremity amputation [4,9,10,11]. Loss of the protective sensation due to DPN is also associated with the loss of ankle reflex and musculature of the leg and foot, resulting in a foot strike that causes the foot to bear excessive and repeated trauma while walking. The mere act of walking on an insensate foot can result in skin damage, leading to a wound [3].

In the face of such findings, identification of the risks factors associated with amputation is of great value to the clinical management of individuals with diabetes. Due to the high level of 
disability of the disease, it is necessary to investigate the main factors involved in the genesis of complications. Through the present cluster analyzes it will be possible to observe the main factors involved in amputation individually and to establish the level of relevance of each one. This differential in the present study will identify key points within the clinical condition of individuals with diabetes which may be used, more specifically, as preventive tools. In this way, the aim of this study was to evaluate the relationship between amputation and risk factors in individuals with diabetes mellitus.

\subsection{Patients and methods}

A cross-sectional study developed within the proposed university in the city of Presidente Prudente, SP, Brazil. The study was approved by the Ethics Committee (protocol number: 10/2011) and all participants signed a consent form prior to the analyzes.

All participants included in this study were recruited from the Diabetic Foot Program, developed in a Brazilian University, over seven years (2007-2014) and all information for this study was extracted from their data. Information on age, sex, disease time and smoking habit was gathered through a semi structured questionnaire. Body mass and height were evaluated using a digital instrument (Welmy ${ }^{\circledR}, \mathrm{W} 110 \mathrm{H}$, Brazil) and body mass index calculated from these anthropometric variables. A metric tape was used to measure the waist circumference and leg length and the presence of ulcers and amputations was assessed through physical examination.

The value of postprandial glucose was collected by means of a capillary blood glucose test using a Biocheck ${ }^{\mathbb{R}}$ device (Biocheck, TD-4225, Taiwan), which provides the blood glucose value using a drop of blood on a strip test, using sterile material which was discarded after use. Fasting glucose was acquired through self-reporting by the volunteers, based on their most recent blood test.

Peripheral diabetic neuropathy was assessed using the MNSI questionnaire, confirmed through scores higher than 8 [12], and the somatosensory sensitivity monofilaments test (SemmesWeinstein, Sorri-Bauruâ, Brazil) at locations corresponding to the dermatomes of the posterior tibial and common peroneal nerves, confirming the presence of peripheral diabetic neuropathy when there was insensitivity to a $10 \mathrm{~g}$ monofilament [13].

For confirmation of peripheral diabetic vasculopathy, evaluation of peripheral circulation was performed using the ankle/ brachial index $(\mathrm{ABI})$, corresponding to the comparison between the upper and lower limbs by means of an ultrasonic Doppler DV-2000 (Medpej ${ }^{\circledR}$, Brazil) and sphygmomanometer (Becton-Dickinson ${ }^{\circledR}$, USA). The ABI was calculated as the ratio between the ankle and brachial systolic pressure, and when less than 0.90 was indicative of peripheral arterial disease. The assessment of blood perfusion was obtained using a finger oximeter (Nonim Onyx ${ }^{\circledR}$, USA) with which values of oxygen saturation in the blood were collected [14]. The test was considered abnormal when the oxygen saturation from the halluces was less than the forefingers by more than two percentage points [14].

\subsection{Statistical analyzes}

The descriptive variables are presented as means, standard deviations and percentages. The association between amputation and the independent variables (risk factors of cardiovascular risk) were analyzed by the chi-square test. The relationship between amputation and the risk factors was analyzed using the Spearman correlation (unadjusted model) and partial correlation adjusted by sex and age. A p value of $5 \%$ was adopted and the software used was SPSS 15.0.

\section{Results}

This study included 165 individuals with type 2 Diabetes Mellitus. The sample characterization is presented in Table 1 through descriptive statistics.

Table 2 presents information on the presence of risk factors for amputation in patients with diabetes. Of the 80 people with type 2 diabetes who used insulin, 13 were amputees, while of the 56 individuals with diabetes and neuropathy, 6 were amputees. Of the 55 participants with diabetic vasculopathy, five had some kind of amputation. However, the analyses of the proportions of these associations were not significant. A significant frequency was observed in patients with diabetes with ulceration; of the 41 participants who presented this condition, $19(\mathrm{p}<0.001)$ were amputees, and when considering the 26 smokers with diabetes, 8 were amputees.

Table 1

Sample characterization of the type 2 diabetes mellitus participants. The variables are presented as mean \pm standard deviation and percentage, Presidente Prudente 2007-2014 ( $\mathrm{n}=165)$.

\begin{tabular}{ll}
\hline Age (years) & $65.73 \pm 6.827$ \\
Body Mass (Kg) & $75.88 \pm 14.84$ \\
Stature (m) & $1.62 \pm 0.10$ \\
Body Mass Index $\left(\mathrm{m} / \mathrm{kg}^{2}\right)$ & $28.92 \pm 6.16$ \\
Waist Circumference $(\mathrm{cm})$ & $98.84 \pm 12.66$ \\
Leg Length (cm) & $85.38 \pm 7.62$ \\
Disease time (years) & $11.47 \pm 8.99$ \\
Postprandial Glycemic (mmol/dl) & $187.34 \pm 67.84$ \\
Fasting Glycemic (mmol/dl) & $147.59 \pm 58.19$ \\
& \\
Sex (\%) & \\
Male & 40 \\
Female & 60 \\
Smoking (\%) & \\
No & \\
Yes & 84.2 \\
Insulin (\%) & 15.8 \\
No & \\
Yes & \\
Ulcer (\%) & 51.5 \\
No & 48.5 \\
Yes & \\
Amputation (\%) & \\
No & \\
Yes & 75.2 \\
Peripheral Neuropathy (\%) & 24.8 \\
No & \\
Yes & \\
Peripheral Vasculopathy (\%) & \\
No & \\
Yes & \\
\hline a Daily use. & 33.9 \\
& \\
\hline & \\
\hline
\end{tabular}

Table 2

Association between amputation and the presence or not of risk factors, Presidente Prudente, 2007-2014.

\begin{tabular}{llll}
\hline Amputation (\%) & & & \\
\hline & No & Yes & P \\
\hline Insulin & $8(9.4)$ & $13(16.2)$ & 0.279 \\
Ulcer & $2(1.6)$ & $19(46.3)$ & $\leq 0.001^{*}$ \\
Neuropathy & $15(13.7)$ & $6(10.7)$ & 0.757 \\
Vasculopathy & $16(15.2)$ & $5(8.3)$ & 0.300 \\
Smoking & $13(9.3)$ & $8(30.7)$ & $0.007^{*}$ \\
\hline
\end{tabular}

Note: ${ }^{*} \mathrm{p}<0.05$. 
Table 3

Relationship between amputation and risk factors of patients with diabetes, Presidente Prudente-SP, 2007-2014 ( $n=165)$.

\begin{tabular}{lllll}
\hline & \multicolumn{2}{l}{ Amputation } & & \\
\cline { 2 - 5 } & \multicolumn{2}{l}{ Crude } & & \multicolumn{2}{l}{ Adjusted: sex and age } \\
\hline & $\mathbf{r}$ & $\mathbf{p}$ & $\mathbf{R}$ & $\mathbf{p}$ \\
Insulin & 0.10 & 0.190 & 0.10 & 0.200 \\
Ulcer & $\mathbf{0 . 5 8}$ & $\geq \mathbf{0 . 0 0 1} *$ & $\mathbf{0 . 5 6}$ & $\geq \mathbf{0 . 0 0 1}$ \\
Neuropathy & -0.04 & 0.581 & -0.25 & 0.748 \\
Vasculopathy & -0.10 & 0.203 & -0.08 & 0.278 \\
Smoking & $\mathbf{0 . 2 3}$ & $\mathbf{0 . 0 0 2}^{*}$ & $\mathbf{0 . 2 1}$ & $\mathbf{0 . 0 0 7}^{*}$ \\
\hline
\end{tabular}

Note: ${ }^{*} \mathrm{p}<0.05$.

Table 3 shows the relationship between the dependent variable (amputation) and the other independent variables in the adjusted model (age and sex). It can be observed that there was a significant relationship between amputation and ulceration and amputation and smoking, even after adjustment for the confounding variables.

Fig. 1 presents the relationship between amputation and the number of cardiovascular risk factors by cluster analyzes. When the sum of risk factors for amputation was analyzed, it was observed that the greater the number of concomitant risk factors, the higher the prevalence of patients with diabetes with amputations. The prevalence of amputation in patients with diabetes with four risk factors was up to $20 \%$ higher when compared to those with only one risk factor.

\section{Discussion}

In the present study, the main predictive risk factors for amputation in this population were ulcers and smoking. Thus, the great contribution of this study involves raising awareness for the prevention and control of the clinical measures of diabetes mellitus to reduce damage from the complications of this disease, such as amputation. Moreover, the higher the number of risk factors for amputation, the greater the prevalence of the outcome in the population studied.

This relation persisted even when was adjusted by the confounders (sex and age). Monteiro-Soares et al. [15] verified, through a systematic review, that the main risk factors for diabetic foot ulceration were age, gender, diabetes duration, body mass index, glycated hemoglobin concentrations and neuropathy, which could also be associated with amputation based on the relationship identified in the present study between ulcers and amputation. Nehring et al. [16] also demonstrated that the male gender, duration of diabetes, height, weight and waist circumference were predictors for the development of diabetic foot, which may represent the root of other complications. In this sense, we highlight the importance of these factors, both in isolation or

\section{Amputation}

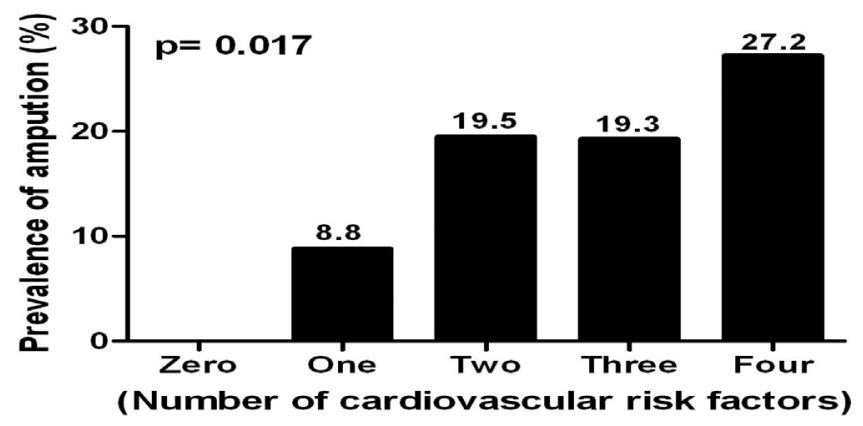

Fig. 1. Prevalence of amputation according to the sum of cardiovascular risk factors, Presidente Prudente 2007-2014 ( $\mathrm{n}=165)$.

*None of the subjects presented five risk factors concurrently. combined, in aggravating the diabetic condition. It is important that further studies be performed, including additional variables in order that the reasons and determinants for the development of diabetic complications can be clarified

Specifically for ulcers, in agreement with the present study, some authors [17] have already indicated that ulcers can be a predictor for lower limb amputation, especially as an ulcer can be a gateway to infectious agents and favor septic complications [18].

On the other hand, there is a scarcity of studies in the literature that clarify the relationship between smoking and amputation. Beaulieu et al. [19] indicated smoking/tobacco abuse as a predictive factor, associated with hospital readmission after some amputations. One possible explanation for this involves the exacerbation of the inflammation response through the many toxic substances associated with this habit and also the suppressive effects on immune cells [20]. These dangerous molecules can reach the bloodstream and from this point, target different tissues [21]. Taking together this immunology of susceptibility, associated with the metabolic disorder and many complications arising from diabetes mellitus, it is possible to see the negative effects of this habit in patients with diabetes.

Additionally, it was identified that the number of risk factors that each patient presented was associated with the prevalence of amputation $(\mathrm{p}=0.017)$. Although working with others variables, Zubair, Malik \& Ahmad [22] affirmed that the accumulation of different factors leads to host immune factors that can lead to host tissue damage and eventually chronic inflammation. Generally, when patients reach this level of complications, they already present a sum of other factors which gradually undermine the homeostatic state of ill health, and this cluster of factors, operating in different modalities, exert a cumulative effect on the clinical condition of the patient.

The present study presents a limitation regarding the number of risk factors included as there are other variables which could be related with the outcome studied. In addition, future studies should involve patients with pre-diabetes and/or in the initial stages of diabetes to explore the effects of these risk factors in a longitudinal design. On the other hand, the results of this study contribute to discussions on public health related to diabetes mellitus and its complications, particularly regarding the analysis of determinants and health conditions and may, thus, contribute to the development of actions at all health prevention levels.

In summary the risk factors for amputation can be predicted for individuals with diabetes mellitus and, in the present study, the main factors were the occurrence of ulcers and the smoking habit. Health promotion actions are required which consider the prevention of risk factors for diabetes.

\section{Conflicts of interest}

None to declare.

\section{Funding sources}

None.

\section{References}

[1] Jhita T, Petrou S, Gumber A, Szczepura A, Raymond NT, Bellary S. Ethnic differences in health related quality of life for patients with type 2 diabetes. Health Qual Life Outcomes 201412(1).

[2] Amos AF, McCarty DJ, Zimmet P. The rising global burden of diabetes and its complications: estimates and projections to the year 2010. Diabet Med 1997;14(Suppl. 5):S1-85.

[3] Margolis DJ, Gupta J, Thom SR, Townsend RR, Kanetsky PA, Hoffstad O, et al. Diabetes, lower extremity amputation, loss of protective sensation, and neuronal nitric oxide synthase associated protein in the Chronic Renal Insufficiency Cohort study. Wound Repair Regener 2013;21:17-24. 
[4] Margolis DJ, Hoffstad O, Nafash J, Leonard CE, Freeman CP, Hennessy S, et al. Location, location, location: geographic clustering of lower-extremity amputation among Medicare beneficiaries with diabetes. Diabetes Care 2011:34:2363-7.

[5] Malay DS, Margolis DJ, Hofstad O, Bellamy S. The incidence and risks of failure to heal following lower extremity amputation for the treatment of diabetic neuropathic foot ulcer. J Foot Ankle Surg 2006;45:366-75.

[6] Lacle A, Valero-Juan LF. Diabetes-related lower-extremity amputation incidence and risk factors: a prospective seven-year study in Costa Rica. Rev Panam Salud Publica 201232(3).

[7] Gamba MA, Gotlieb SLD, Bergamaschi DP, Vianna LA. Amputações de extremidades inferiores por diabetes mellitus: estudo caso-controle. Revista de Saúde Pública 2004;38(3):399-404.

[8] Boulton AJ, Kirsner RS, Vileikyte L. Clinical practice. Neuropathic diabetic foot ulcers. N Engl J Med 2004;351:48-55.

[9] Reiber GE, Vileikyte L, Boyko EJ, del Aguila M, Smith DG, Lavery LA, et al. Causal pathways for incident lower-extremity ulcers in patients with diabetes from two settings. Diabetes Care 1999;22:157-62.

[10] Edwards JL, Vincent AM, Cheng HT, Feldman EL. Diabetic neuropathy: mechanisms to management. Pharmacol Ther 2008;120:1-34.

[11] Boulton AJ. Diabetic neuropathy: classification, measurement and treatment. Curr Opin Endocrinol Diabetes Obes 2007;14:141-5.

[12] Moghtaderi A, Bakhshipour A, Rashidi H. Validation of Michigan neuropathy screening instrument for diabetic peripheral neuropathy. Clin Neurol Neurosurg 2006;108:477-81.

[13] Martinelli AR, Mantovani AM, Nozabieli AJL, Ferreira DMA, Barela JA, Camargo MRD, et al. Muscle strength and ankle mobility for the gait parameters in diabetic neuropathies. Foot 2013;23(1):17-21.
[14] Nozabieli AJ, Martinelli AR, Mantovani AM, Faria CR, Ferreira DM, Fregonesi CEPT. Análise do equilíbrio postural de indivíduos diabéticos por meio de baropodometria. Motricidade 2012;8(3):30-9.

[15] Monteiro-Soares M, Boyko EJ, Ribeiro J, Ribeiro I, Dinis-Ribeiro M. Predictive factors for diabetic foot ulceration: a systematic review. Diabetes Metab Res Rev 2012;28(7):574-600.

[16] Nehring P, Makowski A, Mrozikiewicz-Rakowska B, Sobczyk-Kopcioł A, Płoski $\mathrm{R}$, Karnafel W. Risk factors of diabetic foot of neuropathic origin in patients with type 2 diabetes. Endokrynologia Polska 2015;66(1):10-4.

[17] Bakker K, Apelqvist J, Schaper NC. Practical guidelines on the management and prevention of the diabetic foot 2011. Diabetes Metab Res Rev 2012;28 (S1):225-31.

[18] Lew EJ, Mills JL, Armstrong DG. The deteriorating DFU: prioritising risk factors to avoid amputation. J Wound Care 2015;24(Suppl 2):31-7.

[19] Beaulieu RJ, Grimm JC, Lyu H, Abularrage CJ, Perler BA. Rates and predictors of readmission after minor lower extremity amputations. J Vasc Surg 2015; 62(1):101-5.

[20] Lee J, Taneja V, Vassallo R. Cigarette smoking and inflammation cellular and molecular mechanisms. J Dent Res 2012;91(2):142-9.

[21] Pizarro S, García-Lucio J, Peinado VI, Tura-Ceide O, Díez M, Blanco I, et al Circulating progenitor cells and vascular dysfunction in chronic obstructive pulmonary disease. PLoS One 2014;9(8):e106163.

[22] Zubair M, Malik A, Ahmad J. Incidence: risk factors for amputation among patients with diabetic foot ulcer in a North Indian tertiary care hospital. Foot 2012;22(1):24-30. 